\title{
Identification of gain- and loss-framed cancer screening messages that appeared in municipal newsletters in Japan
}

Tsuyoshi Okuhara ${ }^{1 *}$, Hirono Ishikawa ${ }^{2}$, Hiroko Okada $^{1}$ and Takahiro Kiuchi ${ }^{2}$

\begin{abstract}
Background: Research suggests that cancer screening messages are more persuasive when framed in terms of the costs of not obtaining screening (i.e., loss-framed) than when framed in terms of the benefits of obtaining screening (i.e., gain-framed). However, to what extent these findings have been integrated into public health practice is unknown. To analyze message framing of cancer screening information, the present study examined message framing of cancer screening announcement articles that appeared in municipal newsletters published from 23 wards in central Tokyo, Japan. Two independent raters coded the articles. Gain- and loss-framed sentences in each article were identified, and based on what the sentences conveyed, articles were classified into gain-framed, loss-framed, mixed-framed, and non-framed.

Result: Inter-rater reliability was acceptable (intraclass correlation coefficient $=0.88$ ). Of the 129 articles evaluated, the total number of gain-framed sentences was 87 , while that of loss-framed sentences was six. The total number of gain-framed articles was 32 (24.8\%) while that of loss-framed articles was zero (0\%). Five (3.9\%) articles were mixed-framed. Ninety-two (71.3\%) articles were non-framed.

Conclusions: Cancer screening announcement articles of municipal newsletters were mostly non-framed or gain-framed in 23 Tokyo wards in Japan. The absence of loss-framed articles and only a small number of lossframed messages indicate a missed opportunity to persuade readers to obtain cancer screenings. Loss-framed messages and articles need to be increased to enhance the persuasiveness of cancer screening information in municipal newsletters.
\end{abstract}

Keywords: Message framing, Cancer screening, Municipal newsletter, Persuasion

\section{Background}

Cancer is the leading cause of death in many developed countries, including Japan. In Japan, 805,236 new cases of cancer and 360,963 deaths from cancer were estimated in 2010 and 2012 [1]. Municipalities have been responsible for providing cancer screenings since population-based screening for cancer was introduced under the Health and Medical Service Act for elderly people in 1983. However, cancer screening rates in Japan are lower than those in Western countries and Korea. The screening rates for breast cancer (percentage of females aged 50-69 screened) and cervical cancer (percentage of females aged 20-69

\footnotetext{
*Correspondence: t-okuhara@m.u-tokyo.ac.jp

'Department of Social Medicine, Graduate School of Medicine, The University of Tokyo, 7-3-1 Hongo, Bunkyo-ku, Tokyo 113-8655, Japan

Full list of author information is available at the end of the article
}

screened) in 2010 were $80.4 \%$ and $85.0 \%$ in the United States, $77.0 \%$ and $78.6 \%$ in the United Kingdom, and $63.6 \%$ and $63.8 \%$ in Korea, whereas they were $36.4 \%$ and $37.7 \%$ in Japan, respectively [2]. Other cancer screening rates in Japan (percentage of males and females aged 40-69 screened) are similarly low as follows: gastric cancer is $32.3 \%$, lung cancer is $24.7 \%$, and colorectal cancer is $26.0 \%[3]$.

There are multifactorial barriers to cancer screening, such as knowledge, attitudes and beliefs of patients and providers, socioeconomic factors of patients, the medical system (e.g., accessibility of screening test, lack of tracking and follow-up care, cost of screening test) [4]. A multimodality approach is required to overcome these barriers and improve the screening rates. In particular, effective communication of cancer and cancer screening 
information is of paramount importance [5]. Providing relevant information alone is widely acknowledged as not being sufficient to motivate people to adopt a healthy behavior. Persuasion is inherent in the efforts of health promotion and manifold persuasive communication strategies have been explored [6]. One of those strategies is the framing postulate of Prospect Theory [7].

Prospect theory purports that people tend to take risks when they evaluate options in terms of associated costs but to avoid risks when the same options are described in terms of associated benefits [8]. Hence, when the message of the choice is framed to highlight potential losses, people are more willing to choose risky options to prevent those losses. Conversely, when the choice is framed to highlight potential gains, people are less willing to choose risky options to secure those gains. Health messages can be framed to emphasize either the benefit of adopting a particular behavior (i.e., gain-framed message) or the negative consequence of not adopting a particular behavior (i.e., loss-framed message). Previous research has suggested that how the health message is framed can alter the persuasive impact of the message [7-10].

Rothman and Salovey [7] applied the framing postulate of Prospect Theory to the health promotion domain and proposed that (i) loss-framed messages should be more effective for promoting risky health behavior, such as detection of illness (e.g., obtaining mammography screening involves a higher degree of risk that a serious illness could be discovered) and (ii) gain-framed messages should be more effective for promoting minimally risky health behavior, such as preventive behavior (e.g., increasing physical activity involves little risk). According to this hypothesis, cancer screening messages should be more persuasive when loss-framed, focusing on the negative consequence of not being screened.

A growing body of evidence supports this hypothesis. A previous study showed that women who read a lossframed pamphlet that emphasized the risk of not performing a breast self-examination (BSE) showed more positive attitudes and intentions toward BSE and practiced BSE more frequently than women who received a gain-framed or non-framed pamphlet, or no information [11]. Similarly, women who are exposed to loss-framed messages are six times more likely to obtain a mammogram than those who receive the usual message [12]. Further, loss-framed messages are reported to be more effective in promoting prostate cancer screening [13] and skin cancer screening [14].

The fear appeal (persuasive message that arouse fear) is also one of the persuasive strategies that has been effectively used in health promotion campaigns $[15,16]$. Hale and Dillard suggest that fear appeals should be loss-framed to emphasize negative consequences for not following message recommendations [16]. Thus, lossframed messages are also considered to be useful to utilize the fear appeal.

Although the effectiveness of message framing for health promotion has been reported repeatedly for almost 2 decades, to what extent this finding is used in practice to communicate cancer screening information is unknown. In Japan, most of the municipalities publish municipal newsletters for the residents to disseminate administrative services including health services such as cancer screenings [17]. In fact, municipal newsletters are most frequently mentioned by residents as a source of cancer screening information [18]. Therefore, improving cancer screening announcements that appear in municipal newsletters is important for effective communication of cancer screening information in Japan. This study aimed to analyze message framing of cancer screening announcement articles that appeared in municipal newsletters published in Tokyo, Japan. The secondary aim of this study was to discuss how to improve cancer screening announcements by applying the framing postulate of Prospect Theory.

\section{Methods}

Articles including cancer screening announcements were collected from municipal newsletters that were published in central Tokyo (23 wards) from January to December 2013. Each of the 23 wards publishes newsletters for the residents twice to four times a month. The volume of the newsletters is from four to 16 pages of A3 paper size. We downloaded the PDF data of the municipal newsletters from the website of each ward in April 2014 to use in analyses. During the sampling period, 257 articles including cancer screening announcements were identified. Because some of the articles were posted more than twice, the number of unique articles was 129.

The presence of gain- or loss-framed messages was investigated in the 129 unique articles. Message coding guidelines were created based upon previous studies $[7,19,20]$ (Table 1). Initially, the first author and one of the co-authors conducted a preliminary analysis by applying the coding guidelines to three randomly selected articles to resolve any discrepancies in interpretation. The first author then coded each sentence of all of the 129 articles and identified gain- and loss-framed sentences. The number, mean value, maximum, and minimum of gain- and loss-framed sentences were described. According to the type and presence of framed sentences that were conveyed, articles were classified into four categories: gain-framed articles (i.e., conveying gain-framed and non-framed sentences), loss-framed articles (i.e., conveying loss-framed and non-framed sentences), mixedframed articles (i.e., conveying gain-framed, loss-framed, and non-framed sentences), and non-framed articles 
Table 1 Message coding guidelines and sample messages

\begin{tabular}{|c|c|c|}
\hline \multicolumn{2}{|r|}{ Coding guideline } & \multirow[t]{2}{*}{ Example sentence } \\
\hline Message frame & Emphasis of messages & \\
\hline \multirow[t]{6}{*}{ Gain-framed } & (a) The benefits of cancer screening. & $\begin{array}{l}\text { When you obtain cancer screenings, you are taking advantage of the } \\
\text { best method for detecting cancer early. }\end{array}$ \\
\hline & & $\begin{array}{l}\text { The advantage of detecting cancer early is that you are more likely to } \\
\text { increase your treatment options. }\end{array}$ \\
\hline & & Detecting cancer early can save your life. \\
\hline & (b) The costs avoided by cancer screening. & If a cancer is detected early, it is less likely to be fatal. \\
\hline & & $\begin{array}{l}\text { The advantage of detecting cancer early is that you may need less } \\
\text { radical procedures. }\end{array}$ \\
\hline & & Detecting cancer early can reduce your medical costs. \\
\hline \multirow[t]{5}{*}{ Loss-framed } & (a) The costs of not obtaining cancer screening. & Failing to detect cancer early can cost you your life. \\
\hline & & $\begin{array}{l}\text { The disadvantage of failing to detect cancer early is that you may } \\
\text { need radical procedures. }\end{array}$ \\
\hline & & If cancer is detected late, it is more likely to be fatal. \\
\hline & (b) The benefits missed by not obtaining cancer screening. & $\begin{array}{l}\text { When you avoid obtaining cancer screening, you are failing to take } \\
\text { advantage of the best method for detecting cancer early. }\end{array}$ \\
\hline & & $\begin{array}{l}\text { The disadvantage of failing to detect cancer early is that you may } \\
\text { have fewer treatment options. }\end{array}$ \\
\hline
\end{tabular}

(i.e., conveying only non-framed sentences, and no gainor loss-framed sentences). The number and percentage of each category were calculated. To examine the inter-coder reliability, previous studies typically assessed $10-20 \%$ of the total sample by two independent coders [21-24]. In general, assessing not all but a part of the total sample is beneficial to researchers for making easier to reproduce the study. Hence, we chose the longest article from each of the 23 wards (18\% of the total sample). Then, one of the co-authors independently coded the 23 articles to examine the inter-coder reliability.

Data were analyzed using the Statistical Package for the Social Sciences version 21.0 (SPSS, Chicago, IL, USA). Inter-rater reliability was assessed using the intraclass correlation coefficient (ICC) because the numbers of gainand loss-framed sentences of each article were described by two coders and the number of sentences was a continuous variable.

The study was granted an exemption from requiring ethics approval by the ethical review committee at Graduate School of Medicine, The University of Tokyo.

\section{Results}

Inter-rater reliability was acceptable (ICC $=0.88,95 \%$ $\mathrm{CI}=0.80-0.93)$. The number of letters of the articles varied from 91 to 6,492. The contents of the articles included announcement of the date and time, location, cost of cancer screenings, recommendation to use screenings, and general information about cancer. The types of cancer that featured in the newsletters were mostly gastric, lung, colorectal, cervical, breast, and prostate cancer. Of the 129 articles that were evaluated, the total number of gain-framed sentences was 87, while that of loss-framed sentences was six (Table 2). The total number of gain-framed articles was 32 $(24.8 \%)$ while that of loss-framed articles was zero $(0 \%)$. Five articles $(3.9 \%)$ were mixed-framed. Ninety-two articles $(71.3 \%)$ were non-framed.

\section{Discussion}

Based upon the framing postulate of Prospect Theory, the cancer screening announcement articles that we analyzed were not framed in the most effective way to motivate readers to obtain cancer screenings. The present study showed that most of the articles in municipal newsletters were non-framed (71.3\%). These non-framed articles provided mainly factual information, such as the

Table 2 Frequency of framed messages

\begin{tabular}{lcccc}
\hline \multicolumn{5}{c}{ Sentences } \\
\hline & $\mathbf{N}$ & Mean value (S.D.) & Maximum & Minimum \\
\hline Gain-framed & 87 & $2.3(1.82)$ & 11 & 2 \\
Loss-framed & 6 & $1.2(0.44)$ & 2 & 1 \\
\hline \multicolumn{5}{c}{ Articles } \\
\hline Gain-framed article (a) & & $\mathbf{N}$ & $\%$ \\
Loss-framed article (b) & & 32 & 24.8 \\
Mixed-framed article (c) & & 0 & 0 \\
Non-framed article (d) & & 92 & 3.9 \\
\hline
\end{tabular}

(a) Conveying gain-framed and non-framed sentences.

(b) Conveying loss-framed and non-framed sentences.

(c) Conveying gain-framed, loss-framed, and non-framed sentences.

(d) Conveying only non-framed sentences, and no gain- or loss-framed sentences. 
date and time, location, cost of cancer screenings, and the incidence of cancer. Message framing research has shown that gain- or loss- framed information is more persuasive than simple factual information $[11,25]$. Thus, these non-framed articles may have been less likely to motivate readers to obtain cancer screenings.

According to previous studies [7,11-14,19], loss-framed cancer screening messages are more persuasive than gainframed messages. However, in the present study, of the 129 articles, the total number of loss-framed sentences was only six, which was much fewer than that of gainframed sentences $(\mathrm{N}=87)$. Moreover, the number of lossframed articles was zero (0\%), while there were 32 (24.8\%) gain-framed articles. Although five articles conveyed loss-framed sentences, these articles also conveyed gain-framed sentences (i.e., mixed-framed). Latimer et al. showed that mixed-framed content is less effective in persuasive communication than gain-framed content to motivate participation in physical activity [26]. (As mentioned above, gain-framed messages are considered to be more effective for promoting preventive behavior such as physical activity). Thus, mixed-framed content in the present study may be less persuasive than lossframed content to motivate obtaining cancer screenings. The effectiveness of municipal newsletter articles in persuading people to have cancer screening might have been low.

Our findings are consistent with previous studies suggesting that the messages in health communication are not framed in the most effective way. Messages promoting preventive behavior, such as hand washing and cessation of smoking, could be more persuasive if gainframed [7]. However, Jenner et al. showed that only $41 \%$ of the messages of hand hygiene posters were gainframed and that some posters were mixed-framed [27]. Latimer et al. also showed that most of the smoking cessation print messages were non-framed, and that only $21.6 \%$ were gain-framed [20].

The small portion of loss-framed messages in the present analysis is consistent with the previous study that Wang-Buholzer et al. showed that public health campaigns adopted exclusively gain-framed messages [28]. The small portion of loss-framed messages in the present analysis may be due to the tendency of municipal newsletters to inform health content in a positive manner. Health promotion staff in public institutions tend to be reluctant to use loss-framed messages because they are anxious about that loss-framed messages can engender negative emotional reactions, such as fear. However, loss-framed messages arouse no greater fear than gain-framed messages or non-framed messages [17]. The persuasiveness of cancer screening announcement articles of municipal newsletters may be improved by adopting loss-framed messages as suggested by research.
We suggest three ways to increase loss-framed messages in cancer screening announcement articles. First, loss-framed messages could be increased in the headlines. In the present analysis, most of the headlines of small articles announcing merely date and location information were simply the name of the type of screening such as "Breast cancer screening". Most of the other headlines were gain-framed, such as "Obtain cancer screening for early detection". Loss-framed messages could be increased by inserting a loss-framed message or reframing gain-framed into loss-framed messages in the headlines; for example, a headline such as "Obtain cancer screening for early detection" could be reframed into a loss-framed headline (e.g., "Obtain cancer screening, if you don't want to lose your health").

Second, loss-framed messages could also be increased by supplementing non-framed messages with loss-framed information. An example of this possibility is that nonframed content, such as "One in 14 women suffer from breast cancer. They should have mammography regularly", could be supplemented with loss-framed information (e.g., "One in 14 women suffer from breast cancer. If breast cancer is detected late, it can metastasize to other parts of your body, such as the lymph nodes, bones, lungs and liver, and can threaten your life. You should have mammography regularly").

Third, the loss-framed message could be increased by reframing gain-framed messages into loss-framed messages. An example of this possibility is that a gain-framed message, such as "If cancer is detected and treated early, your physical, mental and economic burden is slight" could be rewritten in terms of losses (e.g., "If cancer is detected and treated late, your physical, mental, and economic burden is heavy"). Another example is as follows: "If a tumor is detected before malignant transformation, the operation is simple and the medical cost is small" could be reframed into "If a tumor is detected after malignant transformation, you need to have a major operation and pay a large medical cost." To integrate message framing research into practice, the framing postulate of Prospect Theory needs to be widely known to the editors and writers of municipal newsletters and municipal health care staff.

The present study is the first study to analyze message framing of cancer screening information material. The main limitation of the present study is the descriptive design. Future studies need to assess the extent to which message framing of municipal newsletter articles affects readers' attitude, intention, and behavior to obtain cancer screening. In addition, to what extent the present findings are generalizable to other cancer screening information materials is unclear. However, the present findings are important because the 23 Tokyo wards have a large population and strong political impact on other municipalities in 
Japan. Further, our findings are not unique to Japan, but are consistent with previous studies finding that public health services mainly use gain-framed messages [28].

\section{Conclusions}

The number of loss-framed articles was zero in our study. In addition, there were fewer loss-framed messages used than gain-framed messages. Cancer screening announcement articles of municipal newsletters in Tokyo are not effectively framed to motivate people to obtain cancer screening. Most of the articles are non-framed or gainframed. Loss-framed messages and articles should be increased to enhance the persuasiveness of the articles and motivate readers to obtain cancer screening.

\section{Competing interests}

The authors declare that they have no competing interests.

\section{Authors' contributions}

$\mathrm{TO}$ and $\mathrm{HI}$ conceived the concept and design of the study. TO prepared the source data. TO and $\mathrm{HO}$ analyzed the data. TO carried out statistical analysis. TO and HI wrote the manuscript. TK supervised the research project. All authors participated in interpretation of the results and writing of the report, and approved the final manuscript.

\section{Acknowledgements}

This study was supported by a JSPS KAKENHI Grant (Number 24390163).

\section{Author details}

'Department of Social Medicine, Graduate School of Medicine, The University of Tokyo, 7-3-1 Hongo, Bunkyo-ku, Tokyo 113-8655, Japan. ²Department of Health Communication, School of Public Health, The University of Tokyo, 7-3-1 Hongo, Bunkyo-ku, Tokyo 113-8655, Japan.

Received: 2 September 2014 Accepted: 25 November 2014 Published: 11 December 2014

\section{References}

1. Cancer_mortality(1958-2013)E.xls and Cancer_incidence(1975-2010)E.xls. In Cancer Statistics in Japan. Japan: Center for Cancer Control and Information Services, National Cancer Center; 1958-2013. http://ganjoho.jp/ pro/statistics/en/table download.html.

2. OECD Health Statistics. 2014. http://stats.oecd.org/index.aspx? DataSetCode=HEALTH STAT.

3. Pref_Cancer_Screening_Rate(2007_2013).xls. In Cancer Statistics in Japan. Japan: Center for Cancer Control and Information Services, National Cancer Center. http://ganjoho.jp/professional/statistics/statistics.html.

4. Womeodu RJ, Bailey JE: Barriers to cancer screening. Med Clin North Am 1996, 80:115-133.

5. Deppen SA, Aldrich MC, Hartge P, Berg CD, Colditz GA, Petitti DB, Hiatt RA: Cancer screening: the journey from epidemiology to policy. Ann Epidemiol 2012, 22:439-445.

6. Stubblefield C: Persuasive communication: marketing health promotion. Nurs Outlook 1997, 45:173-177.

7. Rothman AJ, Salovey P: Shaping perceptions to motivate healthy behavior: the role of message framing. Psychol Bull 1997, 121:3-19.

8. Tversky A, Kahneman D: The framing of decisions and the psychology of choice. Science 1981, 211:453-458.

9. Rothman AJ, Kelly KM, Hartel A, Salovey P: Message frames and illness representations: Implications for interventions to promote and sustain healthy behavior. In The Self-regulation of Health and IIIness Behavior. Edited by Cameron LD, Leventhal H. New York: Routledge; 2003:278-296.

10. Rothman AJ, Bartles RD, Wlaschin J, Salovey P: The strategic use of gain- and loss-framed messages to promote healthy behavior: how theory can inform practice. J Commun 2006, 56(Suppl 1):202-220.
11. Meyerowitz BE, Chaiken $\mathrm{S}$ : The effect of message framing on breast self-examination attitudes, intentions, and behavior. J Pers Soc Psychol 1987, 52:500-510.

12. Abood DA, Coster DC, Mullis AK, Black DR: Evaluation of a "loss-framed" minimal intervention to increase mammography utilization among medically un- and under-insured women. Cancer Detect Prev 2002, 26:394-400.

13. Cherubini $P$, Rumiati $R$, Rossi $D$, Nigro F, Calabrò A: Improving attitudes toward prostate examinations by loss-framed appeals. J App/ Soc Psychol 2005, 35:732-744.

14. Block LG, Keller PA: When to accentuate the negative: the effects of perceived efficacy and message framing on intentions to perform a health-related behavior. J Marketing Res 1995, 32:192-203.

15. Witte $K$, Allen M: A meta-analysis of fear appeals: implications for effective public health campaigns. Health Educ Behav 2000, 27:591-615.

16. Hale $\lrcorner$, Dillard JP: Fear appeals in health promotion campaings. Too much, too little, or just right? In Designing Health Messages. Edited by Maibach E, Parrott RL. California: Sage; 1995:65-80.

17. Ministry of Health, Labour and Welfare, Japan: Gan kenshin no arikata ni kansuru kentoukai chuukan houkoku sho [Study Meeting Interim Report of Cancer Screening Policies]. 2013.

18. Tokyo Metropolitan Government Bureau of Social Welfare and Public Health: Heisei 25 nen do Toukyou-to gan yobou kenshin tou jittai chousa houkokusho [Tokyo Cancer Prevention and Examination Factual Survey Report, 2013]. Tokyo: 2013

19. Banks SM, Salovey P, Greener S, Rothman AJ, Moyer A, Beauvais J, Epel E: The effects of message framing on mammography utilization. Health Psychol 1995, 14:178-184.

20. Latimer AE, Green KE, Schmid K, Tomasone J, Abrams S, Cummings KM, Celestino P, Salovey P, Seshadri S, Toll BA: The identification of framed messages in the New York State Smokers' Quitline materials. Health Educ Res 2010, 25:54-60.

21. Blum D, Rosa D, de Wolf-Linder S, Hayoz S, Ribi K, Koeberle D, Strasser F: Development and validation of a medical chart review checklist for symptom management performance of oncologists in the routine care of patients with advanced cancer. J Pain Symptom Manage. in press. Epub ahead of print

22. Wallace LS, Rogers ES, Turner LW, Keenum AJ, Weiss BD: Suitability of written supplemental materials available on the Internet for nonprescription medications. Am J Health Syst Pharm 2006, 63:71-78.

23. Goodfellow NA, Almomani BA, Hawwa AF, McElnay JC: What the newspapers say about medication adherence: a content analysis. BMC Public Health 2013, 13:909.

24. Kaphingst KA, Zanfini CJ, Emmons KM: Accessibility of web sites containing colorectal cancer information to adults with limited literacy (United States). Cancer Causes Control 2006, 17:147-51.

25. Miller SM, Buzaglo JS, Simms SL, Green V, Bales C, Mangan CE, Sedlacek TV: Monitoring styles in women at risk for cervical cancer: implications for the framing of health-relevant messages. Ann Behav Med 1999, 21:27-34

26. Latimer AE, Rench TA, Rivers SE, Katulak NA, Materese SA, Cadmus L, Hicks A, Keany Hodorowski J, Salovey P: Promoting participation in physical activity using framed messages: an application of prospect theory. $\mathrm{Br} J$ Health Psychol 2008, 13:659-681.

27. Jenner EA, Jones F, Fletcher BC, Miller L, Scott GM: Hand hygiene posters: motivators or mixed messages? J Hosp Infect 2005, 60:218-225.

28. Wang-Buholzer CF, Lomazzi M, Borisch B: Media response to colon cancer campaigns in Switzerland 2005-2007: regional newsletters are the most reliable among the printed media. BMC Res Notes 2010, 3:177.

\section{doi:10.1186/1756-0500-7-896}

Cite this article as: Okuhara et al:: Identification of gain- and loss-framed cancer screening messages that appeared in municipal newsletters in Japan. BMC Research Notes 2014 7:896. 